\title{
A EXPERIÊNCIA URBANA NOS COMENTÁRIOS DE BENJAMIN AOS POEMAS DE BRECHT
}

\author{
Luciano Gatti
}

\begin{abstract}
O artigo aborda os comentários de Walter Benjamin aos poemas do ciclo "Manual para habitantes das cidades" de Bertolt Brecht, a fim de discutir a especificidade da lírica brechtiana no quadro mais geral da reflexão de Benjamin sobre a lírica urbana moderna. Benjamin retoma duas questões decisivas à constituição da obra de Brecht: a sobriedade da linguagem e o ensinamento como forma de transmissão da experiência urbana e política. Esse vínculo entre experiência e transmissão não se reduz à instrução de condições de sobrevivência na cidade grande, mas se constitui, sobretudo, no aprendizado de uma postura crítica perante a cidade. Enquanto a comunicação entre indivíduos isolados é precária e a organização política aproxima-se da ilegalidade, os poemas almejam a constituição de um vínculo entre "eu" e "tu" por meio da reflexão poética da experiência urbana.

PALAVRAS-CHAVE: Walter Benjamin, Bertolt Brecht, lírica urbana, crítica, experiência.
\end{abstract}

A reflexão de Walter Benjamin sobre experiência moderna é um dos fios condutores de sua última década de trabalho. Em seu derradeiro escrito sobre Bertolt Brecht, os comentários de 1938 a 1939 ao ciclo de poemas "Do manual para habitantes de cidades", essa questão de amplo alcance é recuperada por meio de um motivo muito particular da lírica brechtiana: o imperativo do apagamento dos rastros. De um modo geral, esse tema permite a Benjamin retomar, no contexto da lírica brechtiana, motivos encontrados em outro grande ciclo de poemas da lírica moderna, os "Quadros Parisienses" de Charles Baudelaire, sobre os quais Benjamin também escrevia naquela mesma época (Benjamin, 1974a). No conjunto de ensaios sobre o poeta francês, questões como o apagamento de vestígios da experiência individual na experiência coletiva e o consequente sentimento de estranhamento perante à cidade são trabalhadas de modo a elaborar uma apresentação

* Doutor em Filosofia. Professor do Departamento de Filosofia da Universidade Federal de São Paulo.

Estrada do Caminho Velho, 333 Bairro dos Pimentas Guarulhos - São Paulo. Cep: 07252-312. lfgatti@gmail.com da modernidade parisiense a partir da lírica urbana de Baudelaire. No ensaio "Sobre alguns temas em Baudelaire" (1939), por sua vez, tais motivos tendem a convergir no diagnóstico do declínio de uma concepção tradicional de experiência, ou seja, a experiência moldada por vínculos orgânicos entre o indivíduo e a história coletiva e, portanto, oposta à vivência solitária, imediata e entrecortada do habitante da grande cidade, denominada por Benjamin de "vivência do choque".

Diante desse quadro mais amplo da lírica urbana moderna, este texto pretende salientar a especificidade da poesia brechtiana comentada por Benjamin. O objetivo, contudo, não é simplesmente retomar os temas da reflexão sobre Baudelaire a fim de tornar a lírica de Brecht reconhecível no contexto do declínio da experiência. Ao contrário, sem prejuízo desse diagnóstico, trata-se aqui de tentar levar adiante a perspectiva aberta por Benjamin no ensaio "Experiência e pobreza" (1933), ou seja, examinar o modo como autores decisivos das décadas de 1920 e 1930, como Brecht, lidaram com os desafios colocados por essa época de "pobreza da ex- 
periência”. Sem necessariamente endossar termos que tinham uma boa dose de retórica, como o de “barbárie positiva”, por exemplo, a intenção aqui é a de examinar o encaminhamento dado por Brecht a questões como a do vínculo entre o indivíduo e a coletividade com o objetivo de construir uma experiência político-artística capaz de confrontar, de modo crítico, os acontecimentos desses anos. Embora o conceito de experiência não seja expressamente trabalhado nesses comentários à poesia de Brecht, talvez seja possível afirmar que as questões envolvidas apontam para além do diagnóstico do declínio da experiência tradicional: ou seja, dizem respeito à constituição de uma concepção forte de experiência, subjacente ao trabalho crítico, artístico e político desses autores, inclusive ao trabalho crítico e historiográfico do próprio Benjamin. Essa questão compõe o pano de fundo desta apresentação.

Em primeiro plano, vou me deter em duas questões internas ao trabalho de Brecht nesse período da segunda metade da década de 1920: 1) o ensinamento como forma de constituição e transmissão da experiência urbana e política; 2) e a sobriedade da linguagem desenvolvida nesse processo de transmissão. Essas duas questões serão trabalhadas a partir dos pontos extremos do ciclo de poemas "Do manual para habitantes de cidades" (o primeiro e o décimo poemas). Com o intuito de iluminar o entrelaçamento desses pontos, recorrerei ainda ao trabalho teatral de Brecht, mais especificamente à peça didática $A$ medida (1930), que se destaca da sua produção desses anos pelo radicalismo com que lida com a questão da formação do coletivo.

Antes de iniciar o exame dos próprios textos comentados por Benjamin, algumas palavras sobre a forma específica do comentário, a qual é escolhida por ele como a mais adequada ao trabalho crítico com esses poemas. O comentário, diz ele, parte do classicismo de um texto, ou seja, do preconceito que sustenta sua autoridade.

Trata-se de um estado de coisas muito dialético que essa forma arcaica, o comentário, que, ao mesmo tempo, é uma forma autoritária, seja co- locada a serviço de uma poesia que não só não tem nada em si de arcaico, mas também faz frente ao que é hoje tomado como autoridade. (Benjamin, 1974b, p.539).

Benjamin propõe aqui um modo muito particular de considerar Brecht como autor clássico, do qual decorreria o viés crítico da produção brechtiana. Antes de entrar nos detalhes desse classicismo, vale a pena observar que sua proposta é distinta de duas outras maneiras pelas quais a posteridade considerou Brecht como clássico, notadamente em seu período de maturidade. Primeiro, o classicismo como um projeto explícito do Brecht maduro de apropriar-se da cultura passada num movimento de totalização em vista de um novo teatro. Na bibliografia brasileira, vale dar uma olhada no livro de José Antônio Pasta Jr., Trabalho de Brecht, republicado há pouco (Pasta, 2010). Uma segunda atribuição do termo clássico a Brecht é aquele feito por Heiner Müller, que identifica, no Brecht maduro, a emigração para o classicismo. As grandes peças, as grandes parábolas que fizeram a fama de Brecht, teriam surgido a partir do momento de afastamento das lutas sociais que deram um primeiro feitio à concepção de teatro pedagógico. O Brecht clássico é o Brecht do exílio, mais distante do público e da política. O classicismo aqui, assim como para o Goethe de Weimar, seria uma recompensa literária para a ausência da revolução alemã (Müller, 2003) Naturalmente, há diversas conexões entre esses dois usos do conceito de clássico.

Benjamin imprime ao termo "clássico" um sentido um tanto distinto dos mencionados acima; e não só porque seus comentários contemplam poemas escritos antes da tal "emigração para o classicismo” lembrada Müller, poemas como aqueles do ciclo "Do manual para habitantes de cidades". Leitores dos textos de juventude de Benjamin, como o ensaio sobre o romance As afinidades eletivas, de Goethe (1922), se recordarão do par conceitual crítica e comentário, e de seus referentes, teor de verdade e teor material da obra de arte. O comentário, diz o en- 
saio, parte da distância histórica entre a obra e o tempo histórico do crítico. Ele pressupõe, portanto, um duplo sentido de duração ou de vida póstuma da obra: um processo de inevitável envelhecimento dos materiais empregados em sua produção, reforçando, assim, sua historicidade; e a recepção da obra, ou seja, as leituras e preconceitos acumulados nas épocas posteriores à sua produção. Como atividade de cunho histórico e filológico, o comentário prepararia o caminho para a crítica, a qual se dedica propriamente à verdade desses materiais, legível no momento de sua recepção pela crítica atual. Nesse contexto, o "clássico", muito mais que um atributo intrínseco à obra mesma ou um atributo decorrente de sua canonização, é uma categoria de sua historicidade (Benjamin, 1974b).

A partir de meados dos anos 1920, a atenção crescente de Benjamin a obras e artistas contemporâneos talvez explique o abandono, pelo menos de modo explícito, dessa distinção entre crítica e comentário. Diante de escritores recentes, o comentário perderia sua razão de ser, ainda que Benjamin continue prestando atenção à recepção das obras, como o comprova sua polêmica contra a recepção teológica de Kafka (a famosa "carta a Gershom Scholem também é de 1938) (Benjamin, 1992). Pelo mesmo motivo, considerações sobre a recepção e a distância histórica voltam a ocupar Benjamin em considerações metodológicas de seu planejado livro sobre Baudelaire. Em um fragmento de 1938 (mesmo ano dos comentários aos poemas de Brecht, dos ensaios sobre Baudelaire e da carta sobre Kafka), ele se refere à introdução propiciada pela sociedade burguesa à leitura da poesia de Baudelaire. E afirma que, no contexto do processo de transmissão da cultura em perspectiva materialista, realizar uma leitura crítica de Baudelaire também exigiria avaliar esse aprendizado a fim de libertar sua obra de uma consideração da cultura considerada por Benjamin como fetichista, ou seja, que separa a cultura de suas condições materiais de produção e recepção. Não seria descabido encontrar aqui uma recolocação do proble- ma da obra clássica (Benjamin, 1974a, p.1151).

Diante disto, podemos nos perguntar em que medida se justifica uma leitura de Brecht como autor clássico. Em outras palavras: como Benjamin introduz, nesses comentários, a questão da distância histórica necessária ao gênero do comentário? Sua resposta está no enfrentamento da situação histórica presente, ou seja, no conhecimento de que o dia seguinte poderia "trazer destruição em escala tão gigantesca que nós nos veremos apartados dos textos e das produções de ontem como que por séculos" (Benjamin, 1974b, p.540). Reconhecer que uma catástrofe está sendo gestada no tempo presente produz uma nova perspectiva sobre a cultura e a história recentes. Ela introduz, em suma, uma distância em relação ao tempo presente. A produtividade de tal distância não se reduz, contudo, a conferir uma espécie de atualidade anacrônica à forma tradicional do comentário. Ela também permite decifrar a história recente nos poemas do "Manual": a experiência da clandestinidade urbana, tantas vezes evocada no ciclo, ganha contornos históricos precisos pelo viés da experiência do exílio imposta à militância política e intelectual comunista. É essa experiência que orienta a interpretação proposta por Benjamin do poema "Apague os rastros".

\section{Apague os rastros}

Separe-se de seus amigos na estação De manhã vá à cidade com o casaco abotoado Procure alojamento, e quando seu camarada bater: Não, oh, não abra a porta

Mas sim

Apague os rastros!

Se encontrar seus pais na cidade de Hamburgo ou em qualquer outro lugar

Passe por eles como um estranho, vire na esquina, não os reconheça

Abaixe sobre o rosto o chapéu que eles lhe deram

Não, oh, não mostre o rosto

Mas sim

Apague os rastros!

Como a carne que aí está. Não poupe.

Entre em qualquer casa quando chover, sente em qualquer cadeira 
Mas não permaneça sentado. E não esqueça seu chapéu.

Estou lhe dizendo:

Apague os rastros!

Sempre que você disser algo, não diga duas vezes. Encontrando o seu pensamento em outra pessoa: negue-o.

Quem não escreveu sua assinatura, quem não deixou retrato

Quem não estava presente, quem nada falou

Como poderão apanhá-lo!

Apague os rastros!

Cuide, quando pensar em morrer

Para que não haja sepultura traindo onde jaz

Com uma nítida inscrição que o denuncie

$\mathrm{E}$ o ano de sua morte que o entregue!

Mais uma vez:

Apague os rastros!

(Assim me foi ensinado.)

(Brecht, 1968a, p.267-268; 2000, p.57-8)

Em seus comentários, Benjamin insiste, antes de tudo, em uma novidade no contexto da lírica urbana (Whitman, Verhaeren, Baudelaire, Heym). Brecht teria sido o primeiro a situar o habitante urbano em primeiro plano. Até então, a lírica da grande cidade teria feito abstração dessa espécie de morador. Mesmo em Baudelaire, o foco seria a transitoriedade de Paris, e o parisiense só apareceria como portador do estigma dessa transitoriedade.

Ler as circunstâncias do exílio a partir de tal habitante exige, porém, algum cuidado. Benjamin menciona o acerto de alguns críticos em afirmar que o poema teria ganhado um novo sentido após 1933 (ref. Arnold Zweig), mas insiste em que a condição de emigrante não se restringe à daquele que foi forçado a abandonar o próprio país. Ela diz respeito também à situação daqueles que lutam no próprio país em favor da classe social explorada. A situação dos comunistas na República de Weimar é denominada, então, como uma cripto-emigração, uma forma primeira tanto da emigração efetiva quanto da ilegalidade à qual os opositores seriam submetidos. $\mathrm{O}$ imperativo "apague os rastros" seria um mandamento tanto para os ilegais quanto para os intelectuais opostos ao regime.

É por meio desse habitante que a cidade aparece no poema como um campo de batalhas, em duplo sentido, vinculando, na obra de Brecht, a experiência anárquica da luta pela existência (o Brecht anterior do Breviário - Hauspostille) com a perspectiva revolucionária da luta de classes (o Brecht posterior de poemas como "Os três soldados”). O poema articularia ambas não só na elaboração de uma perspectiva de observação distanciada, avessa ao sentimentalismo, mas também na dicção sóbria e fria da linguagem, a qual seria explicitamente tematizada no último dos dez poemas do ciclo. Como diz Benjamin, Brecht é o observador menos sentimental da cidade.

Gostaria agora de realçar esse conceito de “cripto-emigração" para discutir essa posição de observador não-sentimental. Sabemos que a ausência de sentimentalismo na escrita de Brecht se vincula a uma postura político-artística de teor crítico e racional, a qual embasaria o teor pedagógico e esclarecedor de sua produção. O próprio título do ciclo de poemas (Manual) reforça essa intenção. A frieza e a sobriedade da linguagem é um componente essencial à elaboração de uma postura marcada pelo distanciamento, a qual receberia extenso desenvolvimento teórico na década seguinte (1930) (a teoria teatral do efeito de estranhamento é um de seus desenvolvimentos). É nesse contexto que o conceito de cripto-emigração se torna revelador, pois ele não restringe o exílio ao distanciamento geográfico do exilado. Ao contrário, ele ressalta a construção de uma posição distanciada perante a realidade urbana em que se está inserido, posição que, segundo Brecht, seria a única capaz de mobilizar os poucos meios disponíveis em prol do que ele denomina, em muitos textos desse período, especialmente nas peças de aprendizagem (Lehrstücke), de "transformação do mundo". A clandestinidade da cripto-emigração, mais que um apagamento unilateral da individualidade, pode então ser reformulada por Brecht em uma forma de atuação política e de transmissão da experiência urbana. Para entender melhor essa questão, voltemos ao poema. 
Em cada uma das cinco estrofes, o eu lírico evoca a um "tu", em situações marcadas pelo anonimato e pela dissolução de vínculos, dirigindo a ele o mesmo imperativo: caso elas se verifiquem, "apague os rastros". As estrofes iniciais apresentam a exigência de rompimento dos vínculos pessoais sob as condições da existência urbana. As duas primeiras assinalam a entrada na clandestinidade daquele que não pode mais ser visto pelos que o reconheceriam. O chapéu dado pelos pais - símbolo de cuidado e proteção - passa a ser utilizado como instrumento de afastamento de relações. Juntamente com o casaco, ele compõe um vestuário destinado a exercer uma nova função: encobrir as dimensões do corpo e as feições faciais, de modo a transformar o recém-chegado numa figura anônima. Ou ainda: manter o anonimato do recém-chegado. Já o espaço físico (alojamento e cidade) - a noção de moradia urbana - se dissocia da noção de lar (Heim), seja como a casa reconhecível pelos camaradas do morador, seja como a cidade em que se reconhecem origens e identidades. O teto, como indica a terceira estrofe, não é mais que um abrigo temporário, avesso à noção de permanência. ${ }^{1}$

Nas duas últimas estrofes, por sua vez, a clandestinidade física se torna também intelectual e espiritual. Palavras, pensamentos e retratos são índices de permanência, de testemunho, de vínculos, de rastros, enfim, capazes de atestar alguma presença, inclusive para além do momento da morte, como assinala a referência da última estrofe à inscrição na lápide. Como

${ }^{1}$ Cf. o comentário de Lehmann, 2009, p.230: "É justamente nos pais, após a negação do contato, que é colocado o acento patético na exigência repetida. O chapéu que foi presenteado não pode ser esquecido nem 'involuntariamente'. Este chapéu sem sentido, intercambiável, indica uma obrigação, da qual o sujeito da poesia que está sempre partindo, não consegue se livrar. Justamente por ficar como figura enigmática, abrir apenas um campo de conotações (estar vigilante, cuidado, proteção, chapéu velho) o próprio chapéu inclui a contemplação com presentes, como interferência e lacuna, na visão do mundo da fuga. É usada toda a força para o ar e a dádiva, do passado, da geração anterior, mas também para todas as casas, cadeiras e refeições oferecidas, de tomar o seu poder da obrigação. A frieza desta liberdade é paga com subtração e separação. Por isso é sempre um outro - aquele que fala entre parênteses - que indica o dito como se fosse a ele ditado, levando assim a uma separação absoluta para a intenção". portadores de vestígios reconstituíveis até alguma noção de identidade, todos devem ser negados. Essas últimas estrofes não oferecem apenas uma radicalização do imperativo, de modo a reforçar o apagamento completo dos rastros individuais nas criações coletivas. Ao inquirir, de modo retórico, como que para enfatizar a justeza do imperativo, "Como poderão apanhá-lo!", elas introduzem uma linha divisória entre dois campos de confronto. É o que legitima o esforço de Benjamin em traçar uma referência histórica entre esses imperativos de anonimato e a concretude de um problema real, localizável historicamente, a saber, a situação dos militantes comunistas na República de Weimar.

Nas peças de aprendizagem do final da década de 1920, a diretriz do autoapagamento é mobilizada para discutir pressupostos da formação da coletividade ou, mais especificamente, do comprometimento individual em um esforço coletivo. De modos diversos, esse esforço coletivo aparece tanto na orientação emancipatória da técnica e da ciência, produzidas no interior do capitalismo ( $O$ voo sobre o oceano, $A$ peça de Baden Baden sobre o acordo), quanto na luta pela expansão do comunismo contra a exploração vigente nas sociedades capitalistas (A medida). Nessa última peça, o apagamento da própria identidade é uma condição para a luta coletiva. Sabe-se que Brecht utiliza, em A medida, o artifício da peça dentro da peça para examinar a correção de dois comportamentos políticos: o comportamento do "jovem camarada", que coloca em risco a sobrevivência do grupo revolucionário, ao reagir de modo muito emocional e imediatista diante das condições de exploração capitalistas; e o comportamento do grupo revolucionário, os "quatro agitadores", que encenam para o "coro de controle", o "partido", a medida já tomada contra o jovem camarada. Tal medida havia sido o assassinato do "jovem camarada" em prol da sobrevivência do grupo e da continuidade do avanço da luta comunista, decisão que é submetida por meios teatrais ao exame da coletividade, aqui representada pelo recurso ao 
coro. Novamente, como no poema, trata-se de uma constelação formada pelo apagamento da individualidade, o trabalho político clandestino e a ameaça constante de que a descoberta da própria identidade se reverta na própria morte. O apagamento é, portanto, também uma condição de sobrevivência.

A segunda cena da peça se chama "Anulação" (Auslöschung). Os revolucionários, em trabalho ilegal na China a serviço do partido, não devem ser vistos. A clandestinidade é condição do trabalho ilegal, um processo que Brecht encena por meio do uso de máscaras, as quais servem, nessas peças, à apresentação do consentimento de quem as veste em abdicar da própria identidade. O "diretor da casa do partido" dá as máscaras aos agitadores e afirma: "Agora vocês não são mais vocês mesmos. [...] A partir deste momento vocês não são mais ninguém, a partir deste momento, e talvez até seu desaparecimento [...]" (Brecht, 1991, p.241). A exigência de apagamento pode então ser entendida como uma necessidade colocada pelas circunstâncias da luta por esse objetivo coletivo. Além disso, ela é também um gesto de desprendimento em relação a uma noção de identidade anterior ao estabelecimento dessa dialética entre indivíduo e coletividade, dialética calcada sempre na consciência da historicidade da personalidade humana.

O apagamento não é, contudo, imposto pelo partido. Uma questão essencial às peças didáticas como um todo é o consentimento, a manifestação do "estar de acordo", a qual explicita as dificuldades da formação do coletivo. O indivíduo tem de expressar com consciência (o "sim" é dito após momento de reflexão) seu acordo, enquanto o coletivo não deve furtar-se à responsabilidade pelo destino do indivíduo. Encontrase aí uma dupla exigência: de submissão dos interesses individuais às pretensões legítimas da coletividade; e de verificação da legitimidade e razoabilidade das pretensões apresentadas ao indivíduo. As duas questões tocam a competência individual de avaliação de questões de uma extrema seriedade, como a própria sobrevivên- cia. Como pergunta o partido, trata-se de questionar o consentimento com a própria morte e com o ocultamento dos mortos.

Ao contrário da interpretação que predominou em boa parte da recepção dessa peça, Brecht não pretendeu mostrar o partido como a instância anônima e burocrática que deve sobreviver a todo custo ao indivíduo (este é o preconceito negativo formado pela recepção da peça). Ele é, antes de tudo, uma forma de organização dos indivíduos. Como coportador de um processo decisório coletivo, o indivíduo deve aceitar a competência da experiência coletiva, organizada em torno do partido, mas este deve, por sua vez, conquistar essa competência por meio da democracia intrapartidária. Nesse sentido, só tem validade a sabedoria que pode ser produzida coletivamente (Krabiel, 2001). "Seja sábio junto a nós", diz o texto. Este "nós" não indica necessariamente um partido estabelecido, mas o processo de aprendizado coletivo a que a concepção da peça didática busca dar forma cênica.

É nesse contexto de discussão da ação coletiva que o imperativo de "apagar os rastros" (o episódio do "apagamento") ganha uma duplicidade: ele pode indicar tanto a morte física do jovem camarada quanto a clandestinidade da militância comunista. A relação entre indivíduo e coletivo determinará um ou outro resultado. Quem deixa rastros é o jovem camarada que retira sua máscara e revela sua identidade, abandonando o coletivo com o mesmo gesto com que coloca sua segurança em risco. A decisão de matálo durante a fuga e apagar seus traços faciais é a forma assumida pela necessidade de "apagar os rastros", numa situação em que o esforço coletivo é ameaçado pela unilateralidade de um posicionamento individual. A medida é o ato de violência física capaz de restituir os quatro agitadores à situação que permite o trabalho revolucionário, ou seja, à clandestinidade, situação em que o "apagamento" é uma forma de existência ilegal em favor da causa da transformação do mundo. A medida lida, assim, com uma questão decisiva para o Brecht dos final da década de 
1920: a violência na composição dos coletivos: violência contra o individualismo e contra a existência física dos membros desviantes. O Material Fatzer, por sua vez, produzido nessa mesma época, encaminha essa questão de maneira ainda mais radical, ao entrelaçar a decisão de eliminar o membro desviante - o egoísta - no processo de esfacelamento do coletivo, transmitindo, por fim, ao público a responsabilidade de reconstituir a coerência fabular dos acontecimentos que levaram à morte dos desertores. Ecos desses problemas ocupariam posteriormente Heiner Müller, em peças como Mauser e Quarteto. A medida, por sua vez, ainda mantém um arranjo dramático, sustentando pela possibilidade de ensinamento do comportamento correto por meio da discussão do comportamento incorreto do jovem camarada.

Caso retornemos agora ao poema de 1926, podemos notar que a perspectiva pedagógica do "apague os rastros", assim como sua visada coletiva, também está ali presente. Após as cinco estrofes, todas marcadas pelo pathos da clandestinidade, Brecht conclui com um surpreendente verso entre parênteses: "(Assim me foi ensinado)". Esse arranjo formal é recorrente no ciclo: o último verso, sempre entre parênteses, lança uma nova luz sobre versos precedentes, sugerindo ao leitor a necessidade da releitura. Alterando um traço de gênero, o caráter dramático da segunda pessoa no tempo presente cede à natureza épica da terceira pessoa no passado, distanciando as estrofes anteriores e permitindo um novo conhecimento a respeito de seu conteúdo. O traço épico do último verso revela o processo de transmissão dos preceitos sobre o comportamento urbano. As instruções transmitidas a um "tu" recém-chegado são também o conteúdo de um ensinamento transmitido em um tempo passado que, agora, é atualizado pelo ato de passá-lo adiante. Trata-se, portanto, de um processo de transmissão de experiência capaz de estabelecer os vínculos que as circunstâncias adversas da clandestinidade ameaçam vedar.

Essa relação entre "eu" e "tu", entre a pri- meira e a segunda pessoa, constitui a grande dificuldade da compreensão do poema e também seu maior achado poético. A forma poética não institui a autoridade de um poeta que transmite uma visão de mundo ou um conhecimento particular a seus leitores. Essa autoridade do autor é desmobilizada por Brecht. Lembremos da observação de Benjamin de que Brecht se volta contra aquilo que é tomado como autoridade. A figura do poeta é uma dessas formas de autoridade. Um dos achados do poema é, nesse sentido, remover o "eu" e o "tu" do posto de identidades fixas, colocando-os na posição de polos que só se constituem nesse processo de transmissão do ensinamento. A sugestão da segunda leitura retoma, portanto, a reiteração necessária à transmissão de uma experiência de teor coletivo. Um dado técnico reforça esse ponto de vista: os poemas foram pensados para ser gravados e escutados em disco de vinil, criando, assim, também, condições para uma transformação da recepção por meio de sua escuta coletiva.

Os motivos de tal modo de composição do discurso poético vêm à tona no último poema do ciclo.

Quando falo com você
frio e impessoal
com as palavras mais secas
sem te olhar
(eu aparentemente não te reconheço
em tua particularidade e dificuldade especiais)
falo assim apenas
como a realidade mesma
(a sóbria, incorruptível pela tua particularidade
especial
farta da tua dificuldade)
que para mim você parece não conhecer (Brecht, 1968a, p.277).

Entre a primeira e a segunda pessoa, há uma distinção entre dois modos de ver a realidade: o enunciador já reconheceu como é essa realidade, a qual ainda é desconhecida para o "Tu". Adotar a dicção da realidade - fria, impessoal - torna-se então uma forma de ensinamento. Sóbria não é só a realidade, mas também a linguagem perpassada pelo conhecimento dessa re- 
alidade que impõe a clandestinidade àqueles interessados em transformá-lo. No final de $A$ medida, encontramos a seguinte conclusão: "Só ensinados pela realidade é que podemos transformar a realidade" (Brecht, 1991, p.266). É esse ensinamento que dá o tom frio, seco e direto dos poemas desse ciclo.

Mais que uma nova linguagem, a sobriedade ensina também uma nova postura perante a cidade. Termo decisivo tanto para a compreensão do trabalho de Brecht quanto para a interpretação de Benjamin, a postura sóbria é um posicionamento frio e avesso ao sentimentalismo, que permite regular a distância em relação à realidade, de modo a garantir condições de sobrevivência em circunstâncias de trabalho político clandestino. O termo tem conexões tanto políticas como teatrais. Na terceira cena de $A$ medida ("A pedra”), os quatro agitadores instruem o jovem camarada a aproximar-se dos trabalhadores e a ajudá-los a reivindicar melhores condições de trabalho (melhores sapatos, no caso). O sucesso da missão depende, contudo, da observação de um preceito básico: "Não ceda, porém, à compaixão" (1991, p.243). Os leitores da Poética de Aristóteles sabem que a compaixão é uma das duas emoções que compõem o efeito da tragédia sobre o espectador, a catarse. Sabemos também que a crítica de Brecht ao que ele denomina de dramaturgia aristotélica aproxima as noções de catarse e de identificação ou empatia, uma proximidade, a princípio, bem pouco evidente no texto da Poéti$c a$. Identificar-se com o espetáculo é, segundo Brecht, reagir a ele de maneira exclusivamente emocional, o que não deixaria margem ao desenvolvimento de uma postura crítica e reflexiva perante os eventos apresentados.

Em A medida, o comportamento do jovem camarada tem algo dessa empatia. Sua posição inicial também é a de um observador e é como tal que ele será avaliado. Colocado diante do sofrimento alheio, ele cede à compaixão, sente pena dos trabalhadores e reage de modo imediato e irrefletido, colocando em risco o objetivo mais amplo de criar as condições para a erradicação da exploração. Em outras palavras, a peça se vale do personagem do jovem camarada para estudar esse tipo de postura regulada pela empatia. Como indica Benjamin, o personagem brechtiano não oferece um modelo de comportamento - positivo ou negativo - com o qual se possa identificar, mas instrumentos de análise e de correção de uma postura social. Representam, antes, tipos interessados na transformação social, ou a partir dos quais a transformação social pode ser examinada do ponto de vista de um tipo social existente (Benjamin, 1974b, p.506-507).

Nessa peça de aprendizagem, é a postura dos quatro agitadores que torna possível a avaliação da medida tomada. Eles apresentam os eventos ocorridos, assumem os papéis de si mesmos e do jovem camarada, mas mantêm uma posição distanciada dos eventos, sem confundir-se com eles, de modo que outros - o coro, o partido, os espectadores - possam formar uma opinião sobre o ocorrido. Durante a década de 1930, Brecht caracterizaria essa postura como sendo a do ator-demostrador (Brecht, 1968b): ele é aquele que não se confunde com seu personagem e não se deixa levar por suas emoções, mas assume um posicionamento racional diante dele, de modo a atender à função maior de sua atuação: mostrar o que está mostrando, de modo a impedir a recaída do espetáculo em ilusionismo. A postura sóbria é, em suma, um posicionamento distanciado perante os eventos apresentados, conquistado e aperfeiçoado por meio do teatro.

Se voltarmos, agora pela última vez, aos poemas, veremos que a sobriedade da linguagem também diz respeito a um distanciamento perante a cidade. No imperativo "Apague os rastros", há o exercício de certa postura de desapego que propiciaria algo mais que o reconhecimento das condições da clandestinidade impostas pelo trabalho ilegal. Ali também há o ensinamento de condições de sobrevivência que se opõem criticamente à autoridade combatida pela mesma ilegalidade. Nesse sentido, Brecht não escreveu um poema sobre impossibilidade da experiência com- 
partilhada na modernidade, muito menos sobre as condições gerais da vida na cidade grande. Do mesmo modo que os poemas de Baudelaire não se limitam a registrar o declínio da experiência, mas se voltam contra ela, procurando dar o peso da experiência ao mergulho na vivência do choque, também os poemas de Brecht não se prestam a um lamento da distância entre os homens ou à invocação salvadora de sua superação. Tal esforço implicaria a perigosa vizinhança das ideologias idealizadoras da tradição ou do passado. Outros caminhos podem ser encontrados nesses mesmos comentários de Benjamin. Nos poemas mencionados aqui, eles se encontram nesses vínculos entre emigração, clandestinidade e ensinamento, e também estão presentes. no último poema desses comentários, a "Lenda do surgimento do livro Taoteking no caminho de Laotsé para a emigração": nesse poema, diz Benjamin conclusivo, o que aprendemos com a amabilidade e com a gentileza do sábio chinês não é um modo de superar a distância entre os homens, mas de como tornar tal distância mais viva.

(Recebido para publicação em 15 de maio de 2011)

(Aceito em 19 de julho de 2011)

\section{REFERÊNCIAS}

BENJAMIN, Walter. Charles Baudelaire, Ein Lyriker im Zeitalter des Hochkapitalismus. Gesammelte Schriften I-23. Frankfurt am Main, 1974a. Trad. parcial brasileira: Obras escolhidas III. Charles Baudelaire. Um lírico no auge do capitalismo. São Baulo, Brasiliense, 1991.

. Kommentare zu Gedichen von Brecht. Zur form des Kommentars. In: . Gesammelte Schriften II-2. Franjfurt am Main, 1974b

Goethes Wahlverwandschaften. In:

Gesammelte Schriften I-1. Frankfurt am Main, 1974c. (BENJAMIN, Walter. Ensaios sobre Goethe. Trad. Sidney Camargo e Irene Aron São Paulo: Editora 34, 2010).

. Carta a Gershom Scholem. Novos Estudos, São Paulo, Cebrap, n.35, mar.,1992.

BRECHT, Bertolt. Verwisch die Spuren. In:

Gesammelte Werke 8. Frankfurt am Main: Suhrkamp, 1968a. $=($ BRECHT, Bertolt. Poemas 1913-1956. Trad. Paulo Cesar Souza. São Paulo: Editora 34, 2000).

. Cena de rua. Modelo de uma cena do teatro Suhrkamp, 1968b. Gesammelte Werke, Frankfurt am Main, Paulo: Paz e Terra, 1991. v. 3,

KRABIEL, Klaus Dieter. Die Massnahme. In: KNOPF, Jan (Hrsg.) Brecht-Handbuch 2. Stuttgart: Weimer: Metzler, 2001.

LEHMANN, Hans Thies. Golpes de luz sobre o outro Brecht. In: BRECHT, Bertolt. Escritura política no texto teatral, São Paulo: Perspectiva, 2009.

MÜLLLER, Heiner. Fatzer \pm Keuner. In: KOUDELA, Ingrid (Org.) Heiner Müller. O espanto no teatro. São Paulo: Perspectiva, 2003.

PASTA JR., José Antônio. Trabalho de Brecht. São Paulo: Editora 34, 2010. 


\section{URBAN EXPERIENCE IN BENJAMIN'S COMMENTS ON BRECHT POEMS}

\section{Luciano Gatti}

This paper discusses Walter Benjamin's comments on the poems of the cycle 'Handbook for city dwellers" by Bertolt Brecht, to discuss the specificity of Brechtian lyricism in the more general debate about the Benjamin's reflexions on modern urban lyricism. Benjamin takes up two critical issues to the constitution of Brecht's work : the sobriety of language and teaching as a means of transmission of the urban and political experience. This link between experience and transmission can not be reduced to the instruction of conditions of survival in the big city, but it is constituted principally in learning a critical stance towards the city. While communication between isolated individuals is poor, and political organization approaches the illegality, the poems aspire to the establishment of a link between "I" and "you" through a poetic reflection of urban experience.

Keywords: Walter Benjamin, Bertolt Brecht, urban lyrism, criticism, experience.

\section{L'EXPÉRIENCE URBAINE DANS LES COMMENTAIRES DE BENJAMIN SUR LES POÈMES DE BRECHT}

\author{
Luciano Gatti
}

L'article traite des commentaires de Walter Benjamin sur les poèmes du cycle "Manuel pour habitants des villes" de Bertolt Brecht, pour discuter de la spécificité de la lyrique brechtienne dans le cadre plus général de la réflexion de Benjamin sur la lyrique urbaine moderne. Benjamin reprend deux questions essentielles à la constitution de l'œuvre de Brecht : la sobriété du langage et l'enseignement comme moyen de transmission de l'expérience urbaine et politique. Ce lien entre l'expérience et la transmission ne se limite pas à l'énoncé des conditions de survie dans les grandes villes, mais suppose surtout l'apprentissage d'une attitude critique envers la ville. Alors que la communication entre les individus isolés est précaire et que l'organisation politique se rapproche de l'illégalité, les poèmes aspirent à l'établissement d'un lien entre le "moi" et le "toi" grâce à une réflexion poétique de l'expérience urbaine.

Mots-CLÉs: Walter Benjamin, Bertolt Brecht, lyrique urbaine, critique, expérience.

Luciano Gatti - Doutor em Filosofia pela UNICAMP. Professor do Departamento de Filosofia da Universidade Federal de São Paulo. Sua mais recente publicação: “Constelações. Crítica e verdade em Benjamin e Adorno" (Loyola, 2009). 